\title{
Investigation of vibration and fatigue life of mistuned bladed disks
}

\author{
O. Repetckii \\ Irkutsk State Agrarian University n.a. A.A. Ezhevsky \\ Irkutsk, Russia \\ repetckii@igsha.ru
}

\author{
Tien Quyet Nguyen \\ Department of Machine-Building Technologies and \\ Materials \\ Irkutsk National Research Technical University \\ Irkutsk, Russia \\ cavoixanh@mail.ru
}

\author{
I. Ryzhikov \\ Department of Machine-Building Technologies and Materials \\ Irkutsk National Research Technical University \\ Irkutsk, Russia \\ rin111@list.ru
}

\begin{abstract}
This article presents the results of experimental and finite element analysis of mistuned free vibration of bladed disk models. Blade-to-blade variations of bladed disk assemblies result in local zoning of vibration modes as well as amplitude magnifications, which primarily reduces the high cycle fatigue life of turbomachines rotors. Geometrical mistuning and other types of mistuning were investigated to determine the level of these mode localization effects depending on various vibration parameters of a bladed disk. The main objective was to determine the order of mistuned blades in the bladed disk, leading to the largest and smallest change in vibration characteristics. Obtaining dependencies are important for following researches in this field, in particular, for calculating the fatigue life of the real bladed disks.
\end{abstract}

Keywords - vibration; blisk; mistuning; frequencies; localization

\begin{tabular}{ll}
\multicolumn{2}{c}{ Nomenclature } \\
$K$ & stiffness matrix \\
$\delta$ & node displacements \\
$M$ & mass matrix \\
$\omega$ & eigen-frequency of vibration system \\
$N$ & number of substructure \\
$m$ & number of mode shapes
\end{tabular}

\section{INTRODUCTION}

The high performance bladed disks used in today's turbomachines must satisfy strict standards of the resonant response level. Mistuning is one structural characteristic that can significantly impact this level. Therefore research of vibration behaviour of mistuned bladed disks is a very relevant task. Mistuning has been an active area of research for the past more than 40 years. Whitehead and Ewins were first $[14,5]$. Subsequent investigations are connected with following well-known names: Wei and Pierre [16], Griffin [6], Sinha [12], Srinivasan [13] and others. Irretier and Schmidt [7] first presented the finite element model for the free vibration of mistuned bladed discs. In this method, the triangular element for the calculations for a simple geometry system was applied. A full survey of mistuning studies in 25 years (79 papers) from 1-st paper about this phenomenon (Whitehead, 1966) was given by Ewins [5]. The main purpose of his survey was to classify all different studies of mistuning. In addition to the above-mentioned studies, let us present the interest study by Petrov and Ewins [10]. They describe a method for searching for the worst frequency mistuning patterns with highest response levels. They solve the optimisation problem with the use of information about the sensitivity of maximum response levels with respect to mistuning variations. In this paper, an effective analytical method for sensitivity coefficients calculation is described. Analysis of mistuned bladed disks is also described in papers [18-22]. Mistuning in real constructions is a random variable. In this connection, a lot of papers are devoted to stochastic methods of analysis. This area gets a great progress now.

\section{FE ANALYSIS FOR CYCLIC SYMMETRY SYSTEMS WITH MISTUNING}

Most vibration analyses of tuned bladed discs assume a model of only a single blade and it's associated segment of the disc. Often attempts are made to minimise the computation effort required to solve the mistuned assembly case and have been found to be effective tools, capable of representing the dynamics of real assemblies once their tuned system properties are known. Such approach is used in papers by Yang and Griffin [15]. Analyzing the eigenvalue problem of the system with cyclic symmetry without mistuning may be proceeded by solving the next equation:

$$
K-\omega^{2} M \delta=0
$$

For a cyclic symmetry system (CSS), the difference of deflection between the two boundaries of finite element [21] is given by the equation: 


$$
\delta_{S+1}=e^{\mu}, \mu=i 2 \pi m / N
$$

where $i=\sqrt{-1}, S=1, \ldots, N, m=0,1,2 \ldots, N / 2$ for evens $N$ and $m=0,1,2 \ldots,(N-1) / 2$ for odds $N$.

To analyze the CSS with a mistuning effect, the modified perturbation method was suggested in work [16]. In the free vibration case for this method, there is an equation:

$$
\ddot{q}+\omega_{B}^{2} A q=0,
$$

where

$$
\mathbf{A}=\left[\begin{array}{ccccc}
1+2 R^{2}+\Delta f_{1} & -R^{2} & 0 & \ldots & -R^{2} \\
-R^{2} & 1+2 R^{2}+\Delta f_{2} & -R^{2} & 0 & \ldots \\
\cdots & \ldots & \ldots & \ldots & \ldots \\
\cdots & \ldots & \ldots & \ldots & \ldots \\
-R^{2} & 0 & 0 & -R^{2} & 1+2 R^{2}+\Delta f_{N}
\end{array}\right]
$$

where $\omega_{B}$ - nominal blade natural frequency without mistuning, $\omega_{B i}$ - blade natural frequency of $i$-th blade, $\omega_{C}$ - coupling frequency, $R^{2}=\omega_{C}^{2} / \omega_{B}^{2}$ - dimensionless coupling, $\Delta f_{i}=\left(\omega_{B i}{ }^{2}-\omega_{B}{ }^{2}\right) / \omega_{B}{ }^{2}$ - mistuning of $i$-th blade.

$$
\omega_{i}^{*}=\omega_{i}+\Delta \omega_{i}+\Delta^{2} \omega_{i}
$$

Then eigenvalue of a mistuned system may be obtained as:

$$
\omega_{i}^{*}=\frac{\omega_{i}^{2}}{\omega_{b_{i}}^{2}},
$$

where $i=1, \ldots, N, \omega_{i}$ - vector of blade frequency without mistuning (for an ideal structure), $\Delta \omega_{i}$ - increasing vector of blade frequency with the first order mistuning, $\Delta^{2} \omega_{i}$ increasing vector of blade frequency with the second order mistuning. Let us note that to obtain the eigenvalues and deflections of the system with mistuning, one can use the equation [16]:

$$
\delta_{i}^{*}=\delta_{i}+\Delta \delta_{i}+\Delta^{2} \delta_{i} .
$$

where $i=1, \ldots, N, \delta_{i}$ - vector of blade deflection without mistuning, $\Delta \delta_{i}$ - increasing vector of blade deflection with the first order mistuning $\Delta^{2} \delta_{i}$ - increasing vector of blade deflection with the second order mistuning [16].

\section{NUMERICAL RESULTS}

First analysis of mistuned blisks was analysis of blisks, mistuned via discretization. One blade has more fine mesh in comparison with other blades. Due to fine mesh, one has a more flexible model of blade in comparison with other blades. Vibration characteristics of this blade are different in comparison with other blades and, thus let us obtain mistuned blisk.

In Fig. 1 one can see results of free vibration analysis of blisk with 5 blades, using BLADIS+ (Repetskiy [21]) and ANSYS program. One can see that frequencies were changed slightly (about $0,19 \%$ ). But mode shapes were changed considerably.

Mistuning leads to clear orientation and fixation of nodal diameters relative to blisk. In one mode, the nodal diameter traverses across the mistuned blade. This blade does not participate in vibrations, and blisk frequency equals tuned. Other mode has nodal diameter, traversing the perpendicular previous case, and there is frequency change and localization.

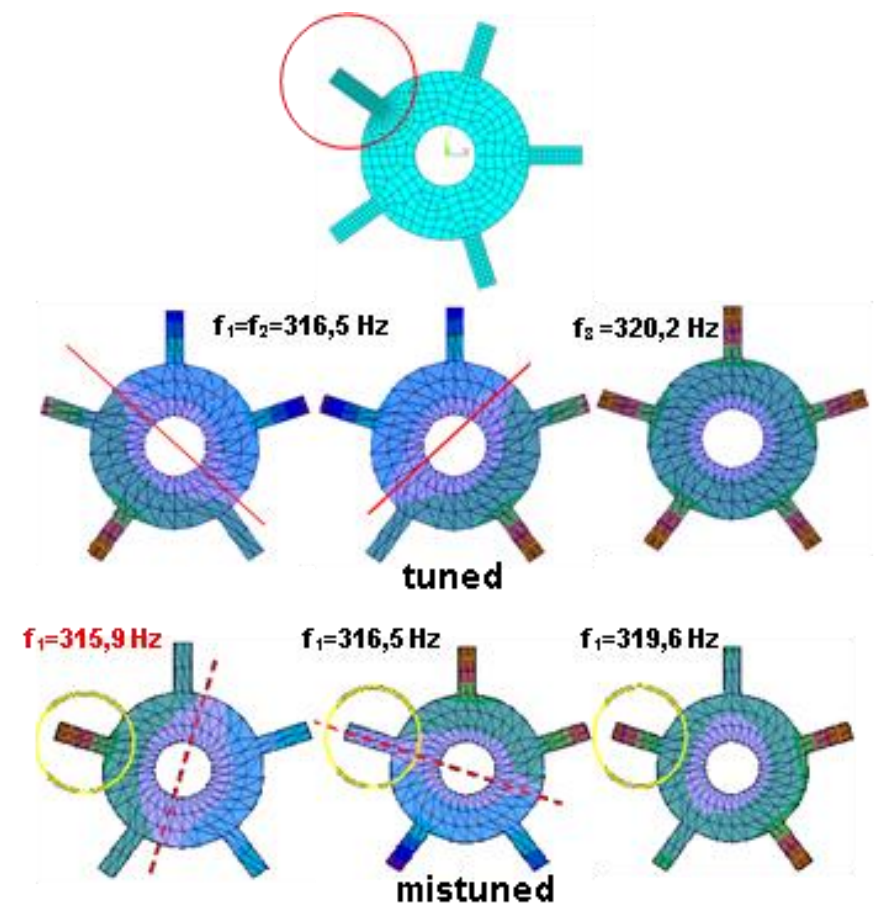

Fig. 1. Mistuning via discretization.

Also the "umbrella" mode has distortion in comparison with tuned blisk.

Fig. 2 presents the mistuning via E-module change. This analysis was carried out in ANSYS. The authors changed Emodule by $5 \%$ for one blade. In Table 1 , there are calculated 
eigenfrequencies; they changed slightly (not more than $0,22 \%)$. The distortion of mode shapes looks like the previous case.

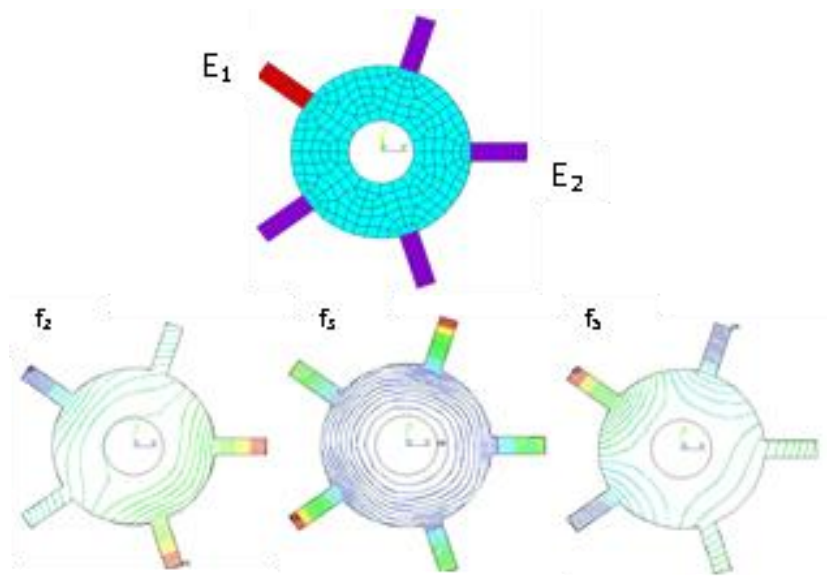

Fig. 2. Mistuning via E-module change.

For the case of geometrical mistuning, let us use blisk, presents in Fig. 3. The length of one blade was changed.

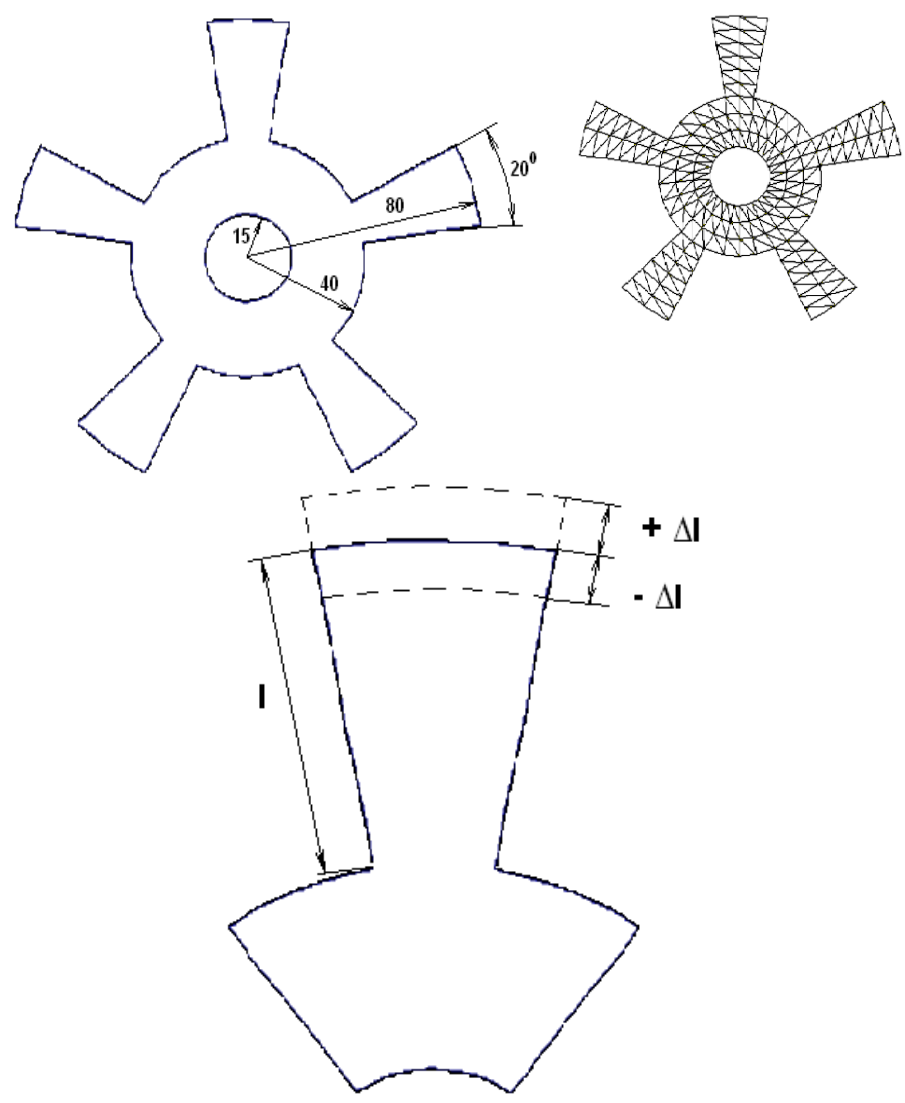

Fig. 3. Model of mistuned blisk.

For tuned blisk, each group of modes has double modes with equal eigenfrequencies. For mistuned blisk, these eigenfrequencies are splitted. One of these modes does not change. For other one can see changes of frequencies
(Fig.4). Let us also obtain vibration localization even by $0,5 \%$ mistuning. With the increase of mistuning strength, there is more localization. And in case with 5\% mistuning, one has the "worst case", when one blade vibrates, but other blades stay immovable.

In case of mistuning via the blade frequency increase, the "worst case" appears for the "umbrella" mode.

Fig. 5 demonstrates impact of geometrical mistuning strength on eigenfrequency. One can see that the law of blisk eigenfrequency variation for the increase of "positive" mistuning is different from the corresponding law for the increase of "negative" mistuning (different dependence).
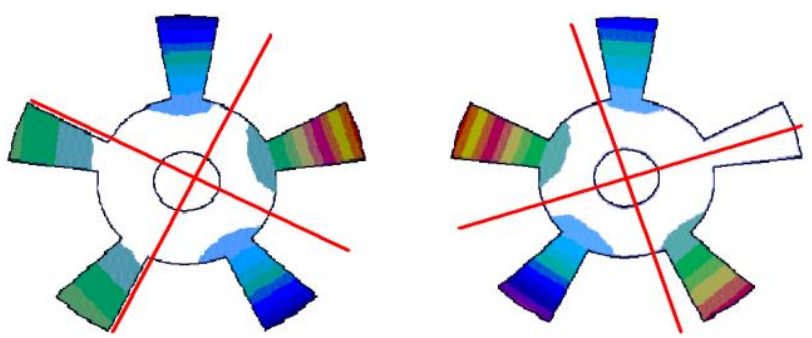

tuned $\left(f_{1}=f_{2}=702,7 \mathrm{~Hz}\right)$
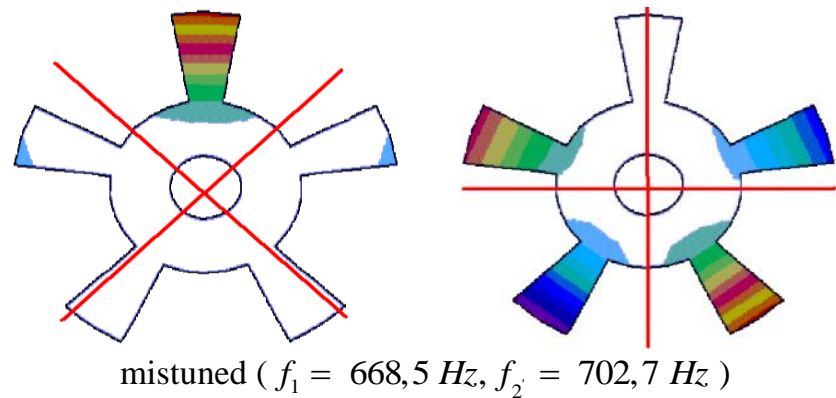

Fig. 4. Geometrical mistuning of blisk.
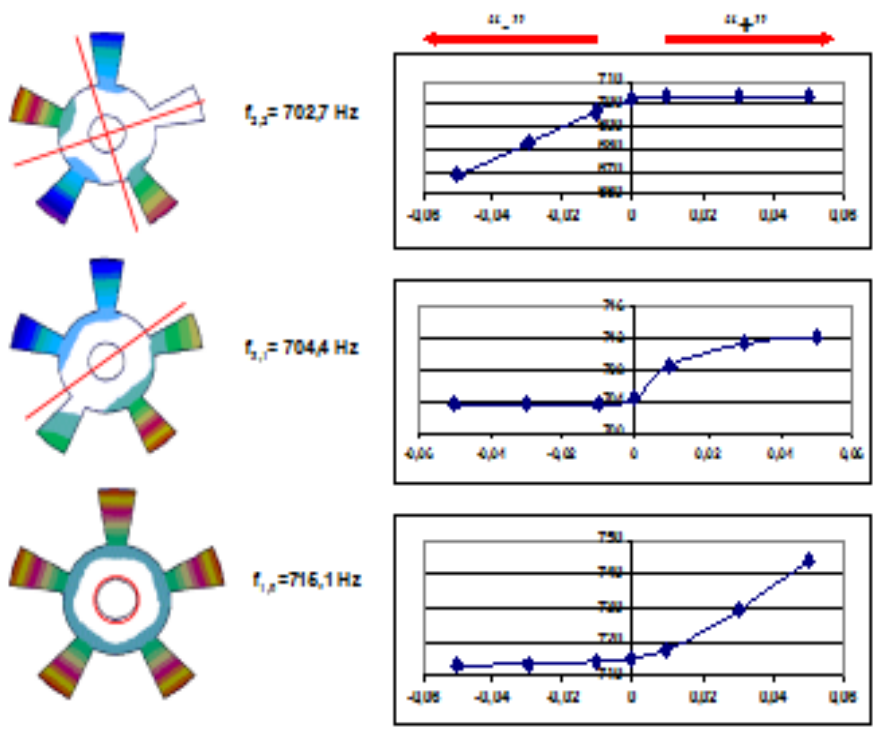

Fig. 5. Impact of geometrical mistuning strength on eigenfrequency. 
Usually in real conditions, not only one blade has mistuning, but all blades differ from nominal eigenfrequency. Usually eigenfrequencies of blades in the set obey Gauss distribution law. Fig. 6 presents eigenfrequencies of blades under Gauss distribution.

In Fig. 7, there are results of calculations of blisk modes and eigenfrequencies of different variants of blades location on the disk. The variant with "saw-tooth" distribution has minimal differences in comparison with tuned blisk.

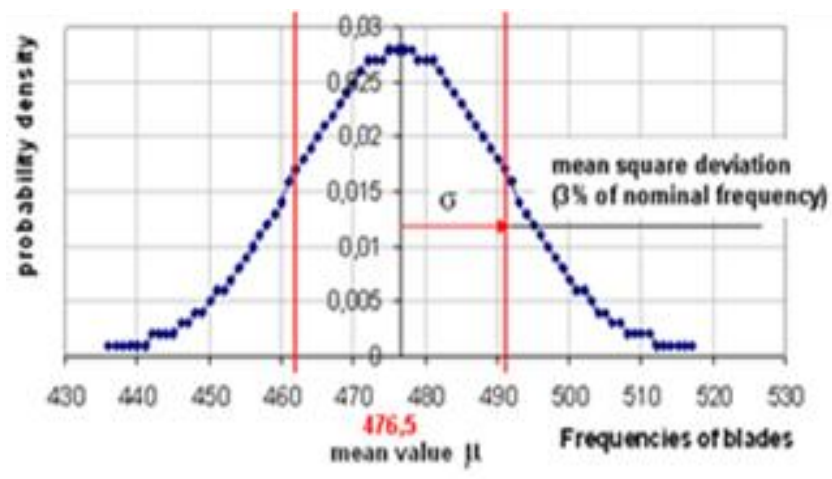

Fig. 6. Gauss distribution of eigenfrequencies.

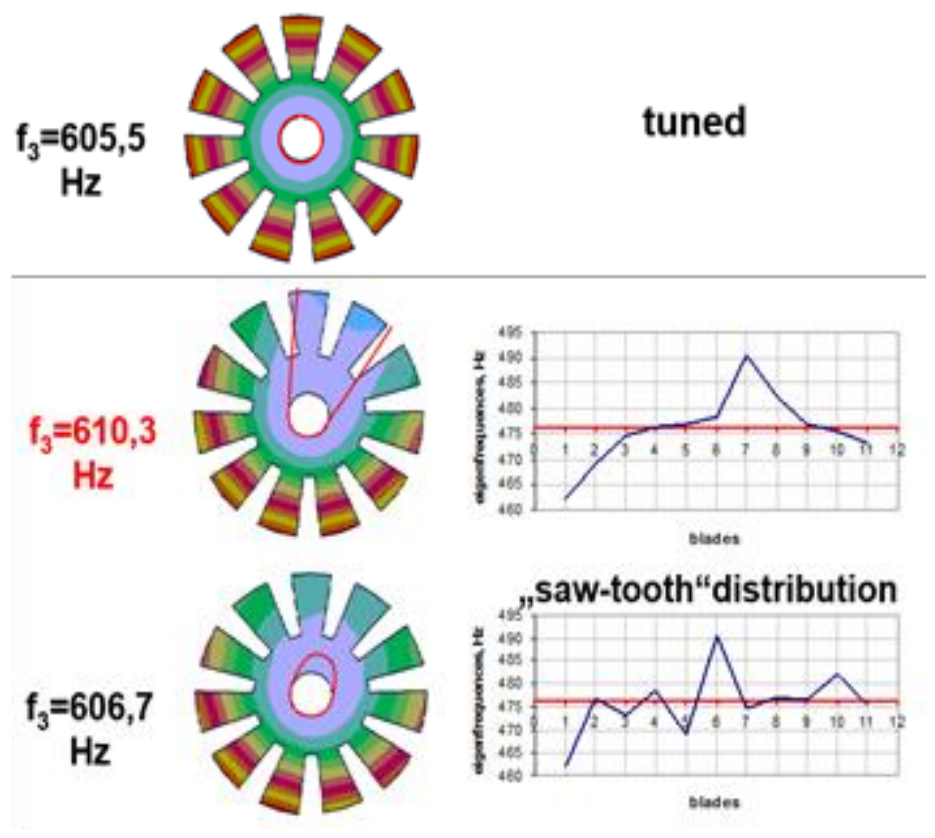

Fig. 7. Variants of blades location on disk.

\section{EXPERIMENTAL MEASUREMENTS OF FREE VIBRATION OF MISTUNED BLISK}

An experiment on the vibration analysis of the mistuned bliskmodel was conducted. The experiment was conducted in the laboratory of the Institute of solid mechanics of TU Dresden. To measure vibration characteristics, the laser scanning vibrometer PSV-400 was used. A flat impeller, having a central hole was cut on the high-precision laser equipment from sheet steel with a thickness of $2 \mathrm{~mm}$. The model had 7 blades.

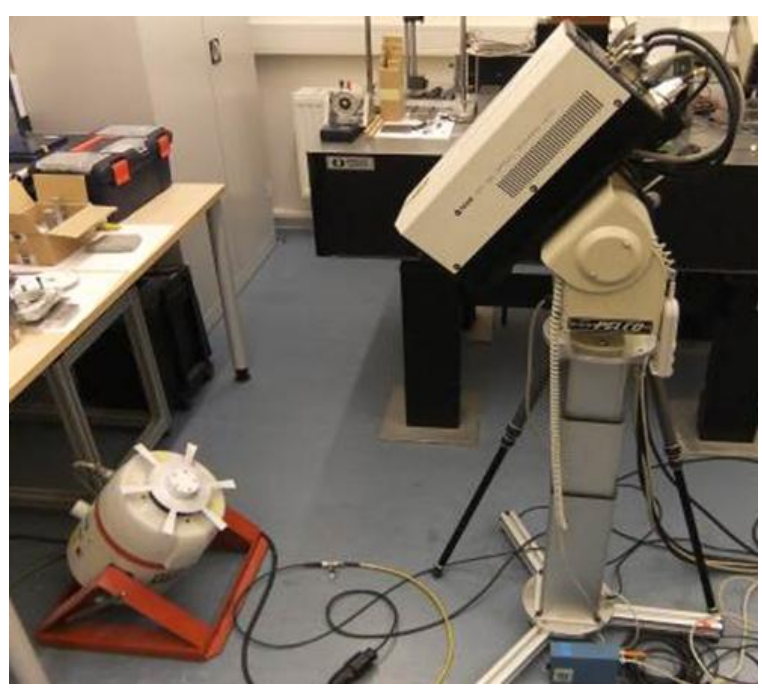

Fig. 8. Experimental equipment.

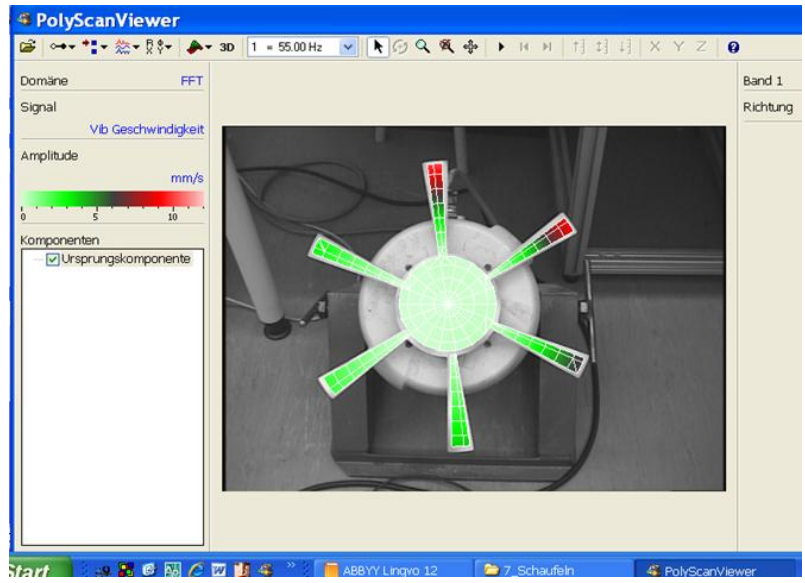

Fig. 8. Oscillating blisk on screen

Vibration measurements of the model without mistuning showed that the accuracy of its manufacture, and fixation did not affect vibrations, and the model is almost symmetrical (Fig. 8, a). The experimental results are in good agreement with the results of calculations in the programs ANSYS and BLADIS+ (Table 1).

Mistuning was introduced by joining the peripheral part of the blades of the segments of the magnetic tape. The mass of each segment was measured on electronic scales to the nearest $0.001 \mathrm{~g}$.

At the beginning, the additional mass was attached to only one of the blisk blades. The measurement results showed that even a small additional mass $(0.1 \mathrm{~g})$ introduces significant changes in the frequency spectrum and mode shapes of the model. For example, on the 2nd form, there is a significant localization of the oscillations when only one blade vibrates, and the remaining ones are almost stationary (Fig. 8, b). 


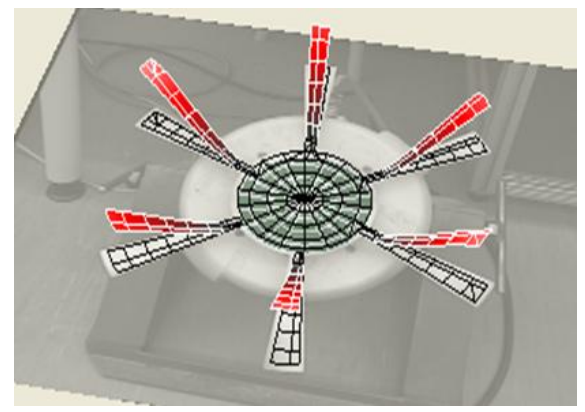

(a)

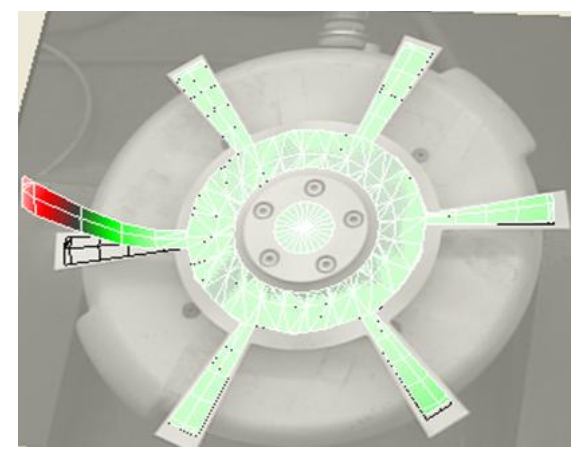

(b)

Fig. 7. (a) - first mode of tuned blisk vibration ; (b) - localization on second mode of mistuned blisk vibration.

The authors investigated 2 variants, where the additional mass was added to all blades of the blisk. In the first case, the magnitude of the additional mass uniformly increased from 0.2 to $1.2 \mathrm{~g}$ in the circumferential direction from blade to blade (0.2-0.4-0.6-0.8-1.0-1.2). In the second case. the mass in the circumferential direction was varied as a "sawtooth" (0.2-1.0-0.6-1.2-0.4-0.8). Comparison of results showed that in the first case, there is a significant localization of vibrations in contrast to the second case. Also for the first case, the difference in frequency for the pair of mode shapes is more significant than for the second one (Table 2).

TABLE I. NATURAL FREQUENCIES OF TUNED MODEL.

\begin{tabular}{|c|c|c|c|}
\hline Mode & Experiment, Hz & ANSYS, Hz & BLADIS+, Hz \\
\hline$f_{1}$ & 85.219 & 88.220 & 86.710 \\
\hline$f_{2}$ & 86.975 & 88.274 & 86.726 \\
\hline$f_{2}$ & 87.250 & 88.274 & 86.726 \\
\hline$f_{3}$ & 92.375 & 90.268 & 89.007 \\
\hline$f_{3}$ & 92.094 & 90.268 & 89.007 \\
\hline
\end{tabular}

TABLE II. NATURAL FREQUENCIES OF MISTUNED MODEL.

\begin{tabular}{|c|c|c|}
\hline Mode & Variant 1, Hz & Variant 2, Hz \\
\hline$f_{1}$ & 79.844 & 80.031 \\
\hline$f_{2}$ & 81.75 & 82.032 \\
\hline
\end{tabular}

\begin{tabular}{|c|c|c|}
\hline Mode & Variant 1, Hz & Variant $\mathbf{2 , ~ H z}$ \\
\hline$f_{2}$ & 83.0625 & 82.344 \\
\hline$f_{3}$ & 88.7188 & 89.219 \\
\hline$f_{3}$ & 90.313 & 90.094 \\
\hline
\end{tabular}

The following steps in the research must be analysis of forced vibration and fatigue life. Fig. 9 demonstrates excitation load modeling.
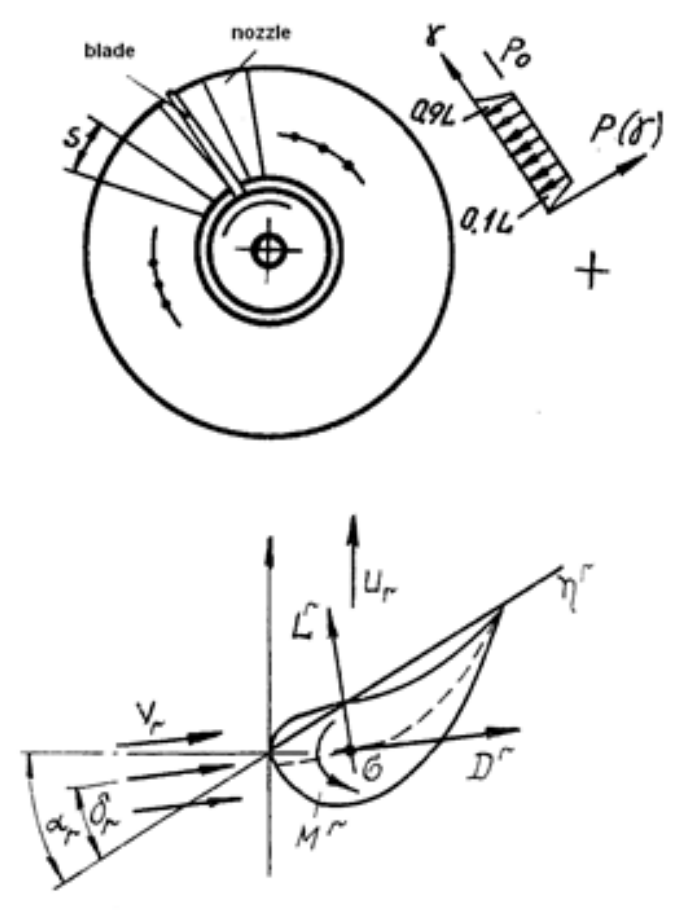

Fig. 9. Excitation load modeling.

For schematization of stresses, the authors realized a two-parameter "rain-flow" method. Fluctuating stresses are calculated for every of the most loaded points of the construction. The most possible damage zone should be chosen out of the calculated tensions; and for this zone there is the analysis of durability. For summarizing the damages, linear hypotheses are used (Palmgren-Miner, Corten-Dolan and Haibach) that allows one to use one or other hypothesis according to the situation because nowadays there is no one universal hypothesis for summarizing the damages.

The actual continuation of this work is the vibration and fatigue life analysis of the axial bladed disk (Rolls-Royce plc. [22]), shown in Fig. 10. 

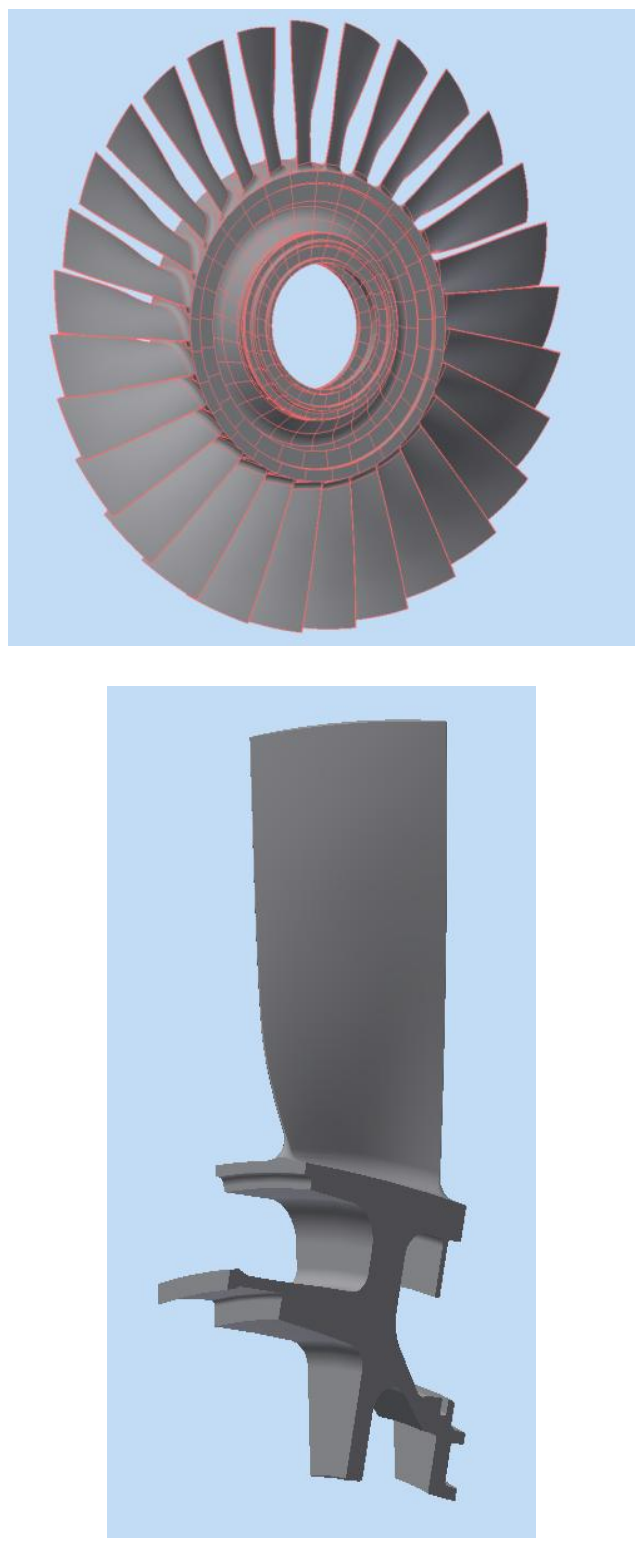

Fig. 10. Rolls-Royce bladed disk and its single sector.

\section{CONCLUSIONS}

The mentioned results of the calculations and measurements demonstrate that even very small mistuning $(0,5 \%)$ leads to splitted modes and localization, when distortion of the harmonic distribution law for circumferential amplitudes of blades is observed. Nodal diameters take broken line form. In case of the set of mistuned blades, minimal mistuning impact on blisk vibration is achieved by "saw-tooth" placement of blades in the disk.

\section{Acknowledgment}

The authors are grateful to Prof. R. Schmidt (TU Dresden) for his valuable comments and suggestions.

\section{References}

[1] Armstrong E.K. An Investigation into the Coupling Between Blades and Disc Vibration, PhD Thesis, Cambridge University, 1955.

[2] Bladh R., Castanier, M.P., Pierre, C. Reduced Order Modelling and Vibration Analysis of Mistuned Bladed Disk Assemblies With Shrouds. Journal of Engineering for Gas Turbines and Power, Vol.121, 515-522, July 1999.

[3] Cottney D.J. The Receptance Analysis of Discs, Blades Shroud Vibration, PhD Thesis, University of London, 1975.

[4] Crawley E.F. Aeroelastic Formulation for Tuned and Mistuned Rotors. AGARDograf ,No.296, pp 19 (1-24) , 1988.

[5] Ewins D.J. Bladed Disc Vibration - A Review of Techniques and Characteristics. Proc. Inst. Mech. Engineers., International Conference of Recent Advances in Structural Dynamics, Southampton, UK, 1980, pp 187-210.

[6] Griffin J.H. On Predicting the Resonant Response of Bladed Disk Assemblies. Trans. ASME, Journal of Engineering for Gas Turbines and Power, Vol. 110, pp 45-50, Jan.1988.

[7] Irretier H. and Schmidt K.J. Mistuned Bladed Disks - Dynamical Behaviour and Computation. Proc. IFToMM Conference of Rotordynamics Problems in Power Plants, Rome, Italy, pp 215-226, Sept. 1982.

[8] Kaza K.R.V. and Kielb R.E. Vibration and Flutter of Mistuned Bladed-Disk Assemblies. AIAA Journal of Propulsion and Power, Vol. 1, No. 5, pp 336-344, Sept-Oct. 1985.

[9] Muszynska A., Jones D.I.G., Lagnese T. and Whitford L. On Nonlinear Response of Multiple Blade System. Shock and Vibration Bulletin, Vol. 51, Part 3, pp 89-110, 1981.

[10] Petrov E.P. and Ewins D.J. Optimal Search for Worst Mistuning Patterns in Mistuned Bladed Discs Based on Large-scale Finite Element Models. Seventh International Conference on Vibrations in Rotating Machinery, 12-14 September, 2000.

[11] Rao J.S. Turbomachine Blade Vibration. Wiley Eastern Limited, New Delhi, 1991.

[12] Sinha A. Calculating the Statistics of Forced Response of a Mistuned Bladed Disk Assembly. AIAA Journal, Vol. 24, No.11, pp 17971801, Nov. 1986.

[13] Srinivasan A.V. Influence of Mistuning on Blade Torsional Flutter. NASA Report, No.CR-165137, 1980.

[14] Whitehead D.S. Effect of Mistuning on the Vibration of Turbomachine Blades Induced by Wakes. Journal of Mechanical Engineering Science, Vol. 8, No. 1, pp 15-21, 1966.

[15] Yang M.-T., Griffin J.H. "A Reduced-Order Model of Mistuning Using a Subset of Nominal System Modes" Journal of Engineering for Gas Turbines and Power, Vol.123, 893-900, Oct. 2001.

[16] Wei S. T., Pierre C. Localization Phenomena in Mistuned Assemblies with Cyclic Symmetry, Part II: Forced Vibrations, University of Michigan, AnnArbor, MI, U.S.A., 1987.

[17] Beirow B. Grundlegende Untersuchungen zum Schwingungsverhalten von Verdichterlaufrädern in Integralbauweise. Aachen: Shaker Verlag, 2009.

[18] Klauke T. Schaufelschwingungen realer integraler Verdichterräder im Hinblick auf Verstimmung und Loaklisierung. Cottbus: Der Andere Verlag, 2008.

[19] Maywald T., Beirow B., Kühhorn A. Mistuning und Dämpfung II. FVVAbschlussbericht, FVV 2014, Issue 1047.

[20] Maywald T., Beirow B., Kühhorn A. Mistuning und Dämpfung II. FVV-Informationstagung Turbomaschinen, FVV 2014, Issue R569.

[21] B. Heiman, V. Gerdt, K. Popp, O.V. Repetckii Mechatronics: components, methods, examples. Novosibirsk: Publishing House of the SB RAS, 2010, 602 p.

[22] Repetckii O., Beirow B. 2016 Application of the analysis of sensitivity for the research of systems with mistuning. Bailal Letter DAAD, №1, 2016, 88-97. 